\title{
Dynamics in Organization: Comparison Study of Learning Organization with Adaptive Organizations
}

\author{
Chu Yi-wei ${ }^{1}$, Ho Meng-chian ${ }^{1}$ \\ College of Social Science, Tunghai University, Taiwan
}

Received: December 29, 2020

Received in Revised: January 19, 2021

Accepted: January 30, 2021

\begin{abstract}
This article discusses the dynamics in organizations, specifically about the comparison of organizational learning with adaptive organizations. This study used a survey method by relying on observational reviews of Organizations $\mathrm{X}$ and $\mathrm{Y}$. Data collection was carried out on all staff from 2 organizations totaling 100 people each, 50 respondents each. The results showed the level of activity in the use of Organizational Technology, especially during the COVID-19 era, the role of information technology was a challenge and an opportunity for organizational performance owners to adapt so that their organizational performance could remain productive and effective. The results showed that the dynamics of the organization require adaptive technology, information technology has an influence on organizational development. This condition requires organizations to continue to learn and provide training in accordance with the times, this is certainly relevant to the concept of learning organization with the impact that requires organizations to acquire and transfer organizational knowledge to individuals in the organization.
\end{abstract}

Keywords: Organizational Dynamics, Organizational Learning, Adaptive Organization

\section{Introduction}

Change in the organization is an important point of view that is considered by managers in an organization. These changes can provide opportunities for organizations to improve performance from the previous one. There are various variations of things that can cause an organization to change, including because organizations need to respond to an ever-changing organizational performance environment (Burke \& Ng, 2006). Today's change has become a demand for every organization. Adaptation to the environment is essential for today's organizations. It would be strange if there were organizations that had not changed at all. In order for change to continue, it needs to be managed as well as possible, starting with designing change actions. To make a good change action plan the organization must have a change target and then create a change action program (Chen et al., 2010).

If the changes to be made are based on problematic conditions facing the organization, the expected condition is to eliminate the problematic conditions so that the organization returns to its ideal condition. Ideal conditions become conditions that are expected to be achieved in a change. Change management is very appropriate in improving the discipline, especially in higher education (Kreber, 2010). The causes and effects caused by changes in the organization always have two effects, namely changes for good and changes towards destruction. Both of these can occur due to several reasons that originate from within or outside the institution concerned. Change management is very important to be applied. However, in reality the process of change that occurs does not always get a positive response. Managers need to understand why organizations must be ready for change: whether innovative or strategic (Herold et al., 2007; Karyotakis \& Moustakis, 2014). Innovative 
change is a continuous improvement within the existing resource framework. Meanwhile, strategic change is a change to do something new.

If the organization does not find the problematic conditions it is facing, it is better to have a far-reaching vision. The organization must be able to set new targets that have never been achieved by the organization. Making these new targets as expected conditions, conditions to be achieved in a change.

\section{Methods}

This study used a survey method by relying on observational reviews of organizations $X$ and Y. Data collection was carried out on all staff from 2 organizations totaling 100 people each, 50 respondents each. Making reports on the results of research that has been done so that the data that has been collected can be understood and analyzed according to the desired objectives after data collection is complete and re-verified then analyzed with mature conclusions. In-depth study of the activities of individual organizations that seek to systematically seek and try new knowledge using scientific methods, which facilitate the problem-solving process in both the concept of learning organization and adaptive organization.

\section{Results and Discussion}

\section{Learning Organization Point of View}

Learning Organization illustrates that learning is a prerequisite for the success of a change and organizational performance (Rose et al., 2009). Learning organizations will help develop organizational capacity which will indirectly have an impact on organizational effectiveness. The effectiveness of this organization as a very important condition for organizational success emphasizes the goals achieved with stability, balance and survival of the organizational functions it stands for. a rather simple framework applied to a complex system. People tend to focus on the partial rather than the whole, and fail to see the organization as a dynamic process. Thus arguments do not work, better appreciation of the system will not lead to more appropriate action. Organizational activities that seek to systematically seek and try new knowledge using scientific methods, which facilitate the problem-solving process. There are two forms of experimentation; first, the form of an ongoing program, carried out in a series of small experiments to gain a better understanding of work, for example, experiments on incentives and work participation or the development of simple technologies to improve the quality of practical work.

The five disciplines that Senge (1995) identifies are key to achieving this type of organization. Senge also emphasized the importance of dialogue in organizations, especially with regard to the discipline of team learning. So dialogue is one of the characteristics of any real conversation in which each person opens himself up to the other, really accepts his point of view as a valuable consideration and enters the other in terms that he understands not as an individual in particular, but the content of the conversation. The aim is not to win arguments but for further understanding.

According to Senge (1995) vision can also foster long-term adherence, which is the basis of the 'fifth discipline in his book. The practice of shared vision involves the skill of digging together the "picture of the future" that commitment is a basic human motivation not just because of one's obedience. Second, Demonstration Projects, are usually broader and more complex than on-going experimentation. These projects are undertaken in the interests of a holistic, broader system, and usually in the context of improving the organization's updated capabilities. The characteristics of the demonstration project are learning by doing, which is 
an initial project of an organization so that from this experience it is hoped that it can be adopted into a wider scale, seeking policies for subsequent projects, and seeking feedback.

Our response or behavior to the environment is influenced by the assumptions that we have in mind about work and organization. Cognitive. The problem arises when we are mentally limited or even malfunctioning, thus hindering organizational development. In learning organizations the mental model is not limited, but is free and can always change. If the organization wants to change into a learning organization it must be able to overcome fears or anxieties to think.

\section{Overview of the Adaptive Organization Aspect}

Adapatability is the ability of an organization that has high performance in a long period of time and is always adaptive and innovative in line with the dynamics of change in its environment. Adaptability literally means the ability to adapt to the surrounding environment, in relation to government institutions or organizations. Adaptability can be said as the ability of the institution to respond to a series of changes that occur in the institution. For humans, the closest and most tangible environment is the physio-organic realm. Both the physical geographic location as a place of residence which more or less affects its psychological characteristics, as well as the biological needs that must be fulfilled, both of which are physio-organic natural environments in which humans adapt to ensure their survival. The organic physio realm is also called the external environment. Adaptation and interference with the external environment is a cultural and social function in organizing human capabilities called technology. The entire procedure of adaptation and interference to the external environment, including skills, technical expertise, and tools ranging from primitive tools to electronic computers is collectively possible.

Organizational change is a process by which the organization moves from its current state to the desired future to increase the effectiveness of its organization. The goal is to find new ways or improve in using resources and capabilities.

The adaptation pattern produces a social change in a society. Social changes that occur in society will have an impact on the growth of a better capacity for the community itself, especially in overcoming life problems (Portes, 2010; de Haan \& Rotmans, 2011). Change also has the opportunity to face resistance (rejection), both individually and organizationally, because it is the most difficult thing to be able to leave old habits that have been firmly attached. The term for this in management is known as change resistance. Rejection of change can occur because there is very little information about the necessity and impact of not making changes. The form of rejection of change does not always appear immediately in standard form.

\section{Dynamics of Change Referring to Learning Organization with Adaptive Organization}

Seeing the reality like this, social change strategy requires integrated efforts, both strategies, programs and change agents that are directly involved with the target groups of change. The basic aspects that are important to consider in making change are the determination of goals, the change event itself and how to make the change. The goals of a change can be different; that is, from a small scale to a larger or wider scale. Systems Learning Organization Model, it is very important to pay attention to the continuity of the learning process in organizations and to achieve success in the organization.

Marquardt (2002) states that learning organizations will not be able to create or survive without understanding and developing five interrelated subsystems, learning, organization, people, knowledge and technology. 


\section{Changes in the dynamics of the Learning Organization}

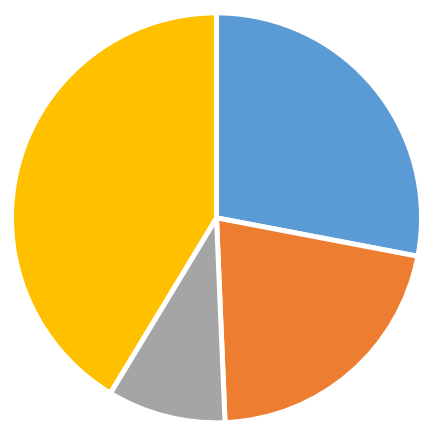

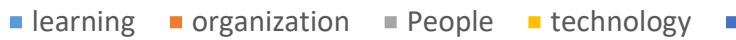

The research results show the importance of technology, especially during the COVID-19 era, the role of information technology is a challenge and opportunity for organizational performance owners to adapt so that their organizational performance can remain productive and effective, both for daily activities, administrative, and supporting other activities. Organization is a place where the learning process occurs, thus making the organization an important subsystem in organizational learning. This condition requires the organization to continue to learn and provide training in accordance with the times. Learning organizations or learning organizations are organizations that are able to create, acquire, and transfer knowledge, and change their behavior to reflect new knowledge and insights (Sange, 1995; King, 2001; Yang et al., 2004; Alipour et al., 2011).

Another alternative option, but the solution will return to the goals of the existing leadership paradigm in each organization. In addition, organizations need to pay attention to the aspects of information technology management, especially regarding the information technology management process. When an organization acquires or merges with another organization, the organization can absorb the methods and procedures of the organization or combine them in its own ways and procedures, so that new knowledge of both processes and personnel is formed.

\section{Dynamics in Adaptive Organization}

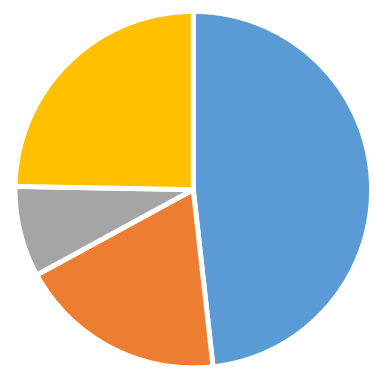

- Adaptive to technology

- Economic conditions

- Organizational Environment Change $=$ Crisis Situation

The results showed that the dynamics of the organization require adaptive information technology to have an influence on organizational development. Technology has influenced work systems in organizations. For example, if you used to make administration using a 
typewriter. Then, the documents are sent by courier or telegram. Now, changing to using computers. Correspondence and other documents can be sent electronically such as e-mail because there is internet facilities. In fact, now computers and the internet have become basic necessities in doing business. And so on: technological developments that occur also affect the work system in the organization. Decision making will be faster. This is because, with the information and communication technology, the required data will be obtained quickly. So that of course it will make the organization or organization more competitive because the impact will be great if the decision making is a bit slow, for example, can lose a lot of orders.

Adaptation is not just technology but a problem of crisis. Identifying the factors causing the crisis serves to determine whether public relations or the organization can handle the crisis immediately or not. If the crisis is difficult to overcome, wasting time, effort, and money, public relations can see another aspect of the crisis which the problem was unimaginable, namely usually an organization that is hit by a crisis or disaster accompanied by the appearance of other problems that were not previously thought. Therefore, the main factors causing such a significant crisis must first be identified.

Organizational dynamics require adaptive to the conditions for covid 19 Organizational responses to online work need to be done and this is relevant to learning organizations which make organizations must acquire and transfer organizational knowledge which provides opportunities and encourages every individual in the organization to continue to learn and expand capacity himself. So it can be said that a learning organization is an organization that is ready to face change.

\section{Conclusion}

Technology especially during the COVID-19 era, the role of information technology is a challenge for organizational leaders in adapting so that their organizational performance can remain productive and effective. According to the results of the study, it shows that the dynamics of the organization require adaptive information technology to have an influence on organizational development. Information technology is a challenge and opportunity for organizational performance owners to adapt so that their organizational performance can remain productive and effective, both for daily activities, administrative, and other supporting activities. Organization is a place where the learning process occurs in order to adapt to the conditions of the organization, which is especially related to the adaptation of technology use but a tactical step in dealing with crisis problems.

\section{References}

Alipour, F., Idris, K., \& Karimi, R. (2011). Knowledge creation and transfer: Role of learning organization. International Journal of Business Administration, 2(3), 61.

Burke, R. J., \& Ng, E. (2006). The changing nature of work and organizations: Implications for human resource management. Human Resource Management Review, 16(2), 8694.

Chen, J. M., Suen, M. W., Lin, M. J., \& Shieh, F. A. (2010). Organizational change and development. Organization Science, 12, 1-13.

de Haan, J. H., \& Rotmans, J. (2011). Patterns in transitions: understanding complex chains of change. Technological forecasting and social change, 78(1), 90-102.

Herold, D. M., Fedor, D. B., \& Caldwell, S. D. (2007). Beyond change management: A multilevel investigation of contextual and personal influences on employees' commitment to change. Journal of Applied Psychology, 92(4), 942. 
Karyotakis, K. M., \& Moustakis, V. S. (2014). Reinvention of the public sector: Total quality management and change management. The European Journal of Applied Economics, 11(2), 30-44.

King, W. R. (2001). Strategies for creating a learning organization. Information Systems Management, 18(1), 12-20.

Kreber, C. (2010). The university and its disciplines: Teaching and learning within and beyond disciplinary boundaries. Routledge.

Marquardt, M. J. (2002). Building the learning organization: Mastering the 5 elements for corporate learning. Nicholas brealey publishing.

Portes, A. (2010). Migration and social change: Some conceptual reflections. Journal of ethnic and migration studies, 36(10), 1537-1563.

Rose, R. C., Kumar, N., \& Pak, O. G. (2009). The effect of organizational learning on organizational commitment, job satisfaction and work performance. Journal of Applied Business Research (JABR), 25(6).

Senge, P. M. (1995). Learning organizations. Cambridge: Gilmour Drummond Publishing.

Yang, B., Watkins, K. E., \& Marsick, V. J. (2004). The construct of the learning organization: Dimensions, measurement, and validation. Human resource development quarterly, 15(1), 31-55. 